\title{
Selective Stimulation of C Fibers by an Intra-Epidermal Needle Electrode in Humans
}

\author{
Naofumi Otsuru ${ }^{1,2, *}$, Koji Inui ${ }^{1}$, Koya Yamashiro ${ }^{1,2}$, Takahiro Miyazaki ${ }^{1,2}$, Ichiro Ohsawa ${ }^{3}$, \\ Yasuyuki Takeshima ${ }^{1}$, and Ryusuke Kakigi ${ }^{1,2}$ \\ ${ }^{1}$ Department of Integrative Physiology, National Institute for Physiological Sciences, Okazaki 444-8585, Japan \\ ${ }^{2}$ Department of Physiological Sciences, School of Life Sciences, Graduate University for Advanced Studies, Hayama, \\ Kanagawa, Japan \\ ${ }^{3}$ The first Department of Surgery, Mie University School of Medicine, Tsu 514-8507, Japan
}

\begin{abstract}
We recorded evoked potentials (EPs) induced by intra-epidermal electrical stimulation using a needle electrode with specific parameters. We identified the fibers activated by this specific stimulation by assessing the conduction velocity $(\mathrm{CV})$ of the peripheral nerve. The EPs were recorded from the $\mathrm{Cz}$ electrode (vertex) of the International 10-20 system in ten healthy male subjects. The dorsum of the left hand and forearm were stimulated with an intensity of 0.01 $\mathrm{mA}$ above the sensory threshold. The mean P1 latency of EPs for the hand and forearm were $1007 \pm 88$ and $783 \pm 80 \mathrm{~ms}$, respectively, and the $\mathrm{CV}$ estimated from the latency of $\mathrm{P} 1$ was $1.5 \pm 0.7 \mathrm{~m} / \mathrm{s}$. The $\mathrm{CV}$ indicated that the fibers activated by the stimulation were $\mathrm{C}$ fibers. Since the method of stimulation is convenient and non-invasive, it should be useful for investigating the functions of small fibers.
\end{abstract}

\section{INTRODUCTION}

In studies of sensory systems, a well-controlled stimulus is required to activate the system being examined. An experimental stimulus should be quantifiable, and reproducible (regularity of intensity and time distribution). Additionally, for clinical application, safety, low cost, and simplicity of use are required. Regarding the nociceptive system, no method of stimulation fulfilling these requirements is available, a technical drawback that has prevented progress within this field. The selective activation of $\mathrm{C}$ fibers with little or no concurrent activation of other sensory modalities is particularly difficult.

Various techniques (for review, see [1]) have been used to investigate $\mathrm{C}$ fiber-related cerebral processing [2-8] as well as conduction velocity (CV) [9], each with its own strengths and weaknesses.

The most common way of activating $\mathrm{C}$ fibers is to use a laser to stimulate a tiny area of skin [10]. Lasers can stimulate $\mathrm{C}$ fibers specifically with minimal effects on other fibers, but are expensive and hard to control. Electrical stimulation is also useful for investigating the nociceptive system, since the equipment is easier to use and the method itself is non-invasive. Despite its technical advantages, however, conventional electrical stimulation activates thicker fibers at a lower current intensity than $\mathrm{C}$ fibers.

We have developed a method of intra-epidermal

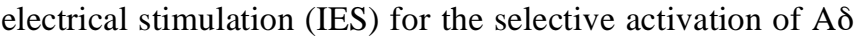

*Address correspondence to this author at the Department of Integrative Physiology, National Institute for Physiological Sciences, Okazaki 4448585, Japan; Tel: +81 56455 7811; Fax: +81 56452 7913;

E-mail: ootsuru@nips.ac.jp fibers [11-16]. Since this method is easy to control, does not require special equipment, and provides a steep rise of stimulation, it would be good for studying the $\mathrm{C}$ fiber nociceptive system if it could activate $C$ fibers selectively. We noticed in previous studies that IES actually activates C fibers when a stimulus intensity higher than the threshold for A $\delta$ fibers is used. Similar results were reported by Nilsson $e t$ al. [17] and Nilsson and Schouenborg [18] who used a needle-like electrode. However, this indicates that the stimulus inevitably activates A $\delta$ fibers at the intensity necessary to activate $C$ fibers. Here we report that IES can activate cutaneous $\mathrm{C}$ fibers selectively when specific parameters are employed.

\section{METHODS}

\section{Subjects}

The experiments were performed on ten healthy male volunteers (25-43 years). The study was approved in advance by the Ethics Committee of the National Institute for Physiological Sciences, Okazaki, Japan, and written consent was obtained from all the subjects.

\section{Stimulation}

We used a method of intra-epidermal stimulation (IES) developed in our laboratory for the selective activation of Aठ fibers [12]. For IES, we used a concentric bipolar needle electrode (Nihon Kohden, Tokyo, Japan) which consisted of an outer ring $1.2 \mathrm{~mm}$ in diameter and an inner needle that protruded $0.1 \mathrm{~mm}$ from the outer ring. For the selective stimulation of C-fibers, the following parameters were used: 1) The anode was the inner needle and the cathode was the outer ring. 2) The electric pulse was a triangular wave with a rise and fall time of $1 \mathrm{~ms} .3$ ) The stimulation was a train of 
Subject 2

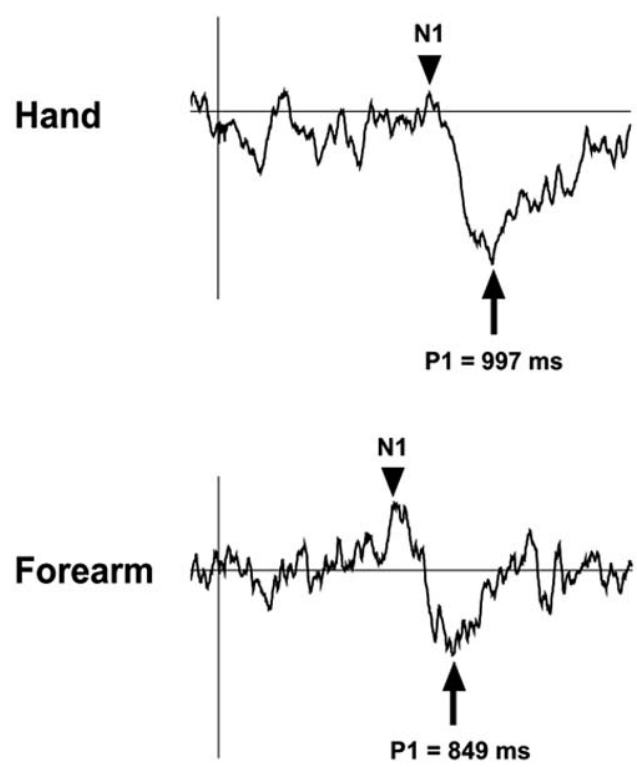

Grand-average
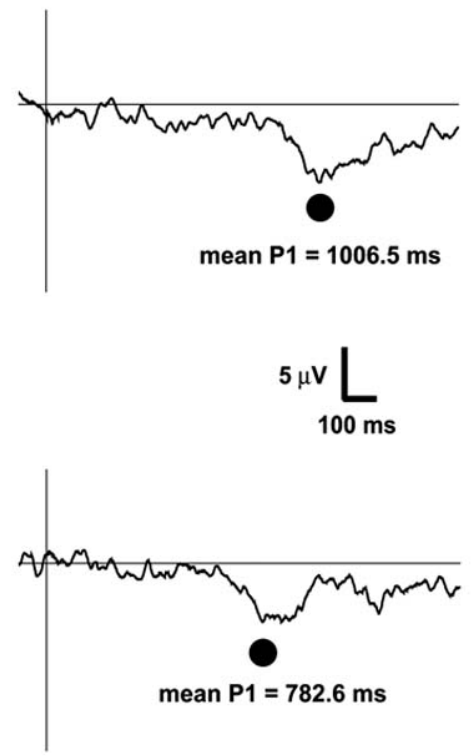

Fig. (1). Evoked potentials following intra-epidermal electrical stimulation recorded at Cz. Waveforms of evoked potentials in a representative subject (left) and grand-averaged waveforms (right). Arrowheads and arrows indicate the peak latency of the negativity and positivity, respectively. Circles in the right traces indicate the mean peak latency.

three pulses with an interstimulus interval (ISI) of $20 \mathrm{~ms} .4$ ) Three electrodes $10 \mathrm{~mm}$ apart were used for augmentation of the response. These parameters were determined based on results of preliminary experiments showing that 1) the standard cathodic stimulation always activated $\mathrm{A} \delta$ fibers at a lower intensity than that for $\mathrm{C}$ fibers, 2) a single pulse of anodal current rarely elicited $\mathrm{C}$-fiber-related brain potentials or sensations while a train of 3-5 pulses was very effective at augmenting the response of $\mathrm{C}$ fibers, 3) thicker fibers seemed to prefer a steeper rise in the pulse, 4) a train of pulses with an ISI shorter than $20 \mathrm{~ms}$ more effectively augmented the activation of thicker fibers than $\mathrm{C}$ fibers, and 5) multiple electrodes were sometimes useful to elicit clear sensations due to the activation of $\mathrm{C}$ fibers. These results are generally consistent with the findings that 1) an anodal current is theoretically effective at stimulating cutaneous fibers running vertical to the skin's surface [19] such as branches of C-fibers innervating the epidermis [20, 21], 2) a pulse of longer duration is necessary to stimulate thinner fibers [22] and 3) a substantial spatial and temporal summation of $\mathrm{C}$-fiber impulses is required to produce painful sensations [23, 24].

The electrical stimulus was applied to the dorsum of the left hand and forearm. The stimulation was started at with an intensity of $0.01 \mathrm{~mA}$ and increased in steps of $0.01 \mathrm{~mA}$ until the subject felt a sensation (threshold). Subjects were instructed to press a button quickly when they felt any sensation and the reaction time (RT) was measured. The mean sensory threshold was $0.04 \pm 0.01$ and $0.04 \pm 0.01 \mathrm{~mA}$ at the hand and forearm, respectively. After confirming that the $\mathrm{RT}$ was in the range of $\mathrm{C}$ fiber transmission (700$1500 \mathrm{~ms}$ ), we recorded evoked potentials (EPs) following IES at an intensity $0.01 \mathrm{~mA}$ above the sensory threshold. At this intensity, single or double pulses did not elicit any sensations or EPs.

\section{Recording of Evoked Potentials}

EEG signals were recorded from the $\mathrm{Cz}$ electrode referenced to the linked earlobes (A1-A2) of the International 10-20 system. A pair of electrodes placed on the supra- and infra-orbit of the right eye was used for recording electro-oculograms. The impedance of the electrodes was kept below $5 \mathrm{k} \Omega$. The EEG signals were recorded with a bandpass filter of $0.1-100 \mathrm{~Hz}$ at a sampling rate of $1000 \mathrm{~Hz}$. The window of analysis was from $100 \mathrm{~ms}$ before to $1500 \mathrm{~ms}$ after the stimulus onset. The $100-\mathrm{ms}$ period before the stimulus was used as the DC baseline. Since the sensation elicited by the stimulation was relatively weak, the subject was asked to attend the stimulus. At least ten artifact-free responses were collected and averaged for each stimulation site.

The peripheral CV was calculated by dividing the difference in peak latency between the EP responses following the hand and forearm stimulation, by the distance between the two sites. Data were expressed as the mean \pm SD.

\section{RESULTS}

The stimulation did not elicit a $\mathrm{C}$ fiber-related sensation or EPs in two of ten subjects. Therefore, EP data obtained from eight subjects were used for the analysis. The sensations produced by IES were a weak painful sensation described as "flicking", "burning", or "long-lasting weak pricking" $(\mathrm{n}=4)$, and a light touch sensation described as a "faint touch" or "light pressure" $(n=4)$.

Representative EP waveforms of a single subject and the group-averaged waveforms are shown in Fig. (1). Similar to previous studies using laser stimulation [25], the stimulation evoked a negativity followed by a positivity (P1). However in some subjects, the negativity was unclear and its peak 
Table 1. Peak Latency of EPs and CV

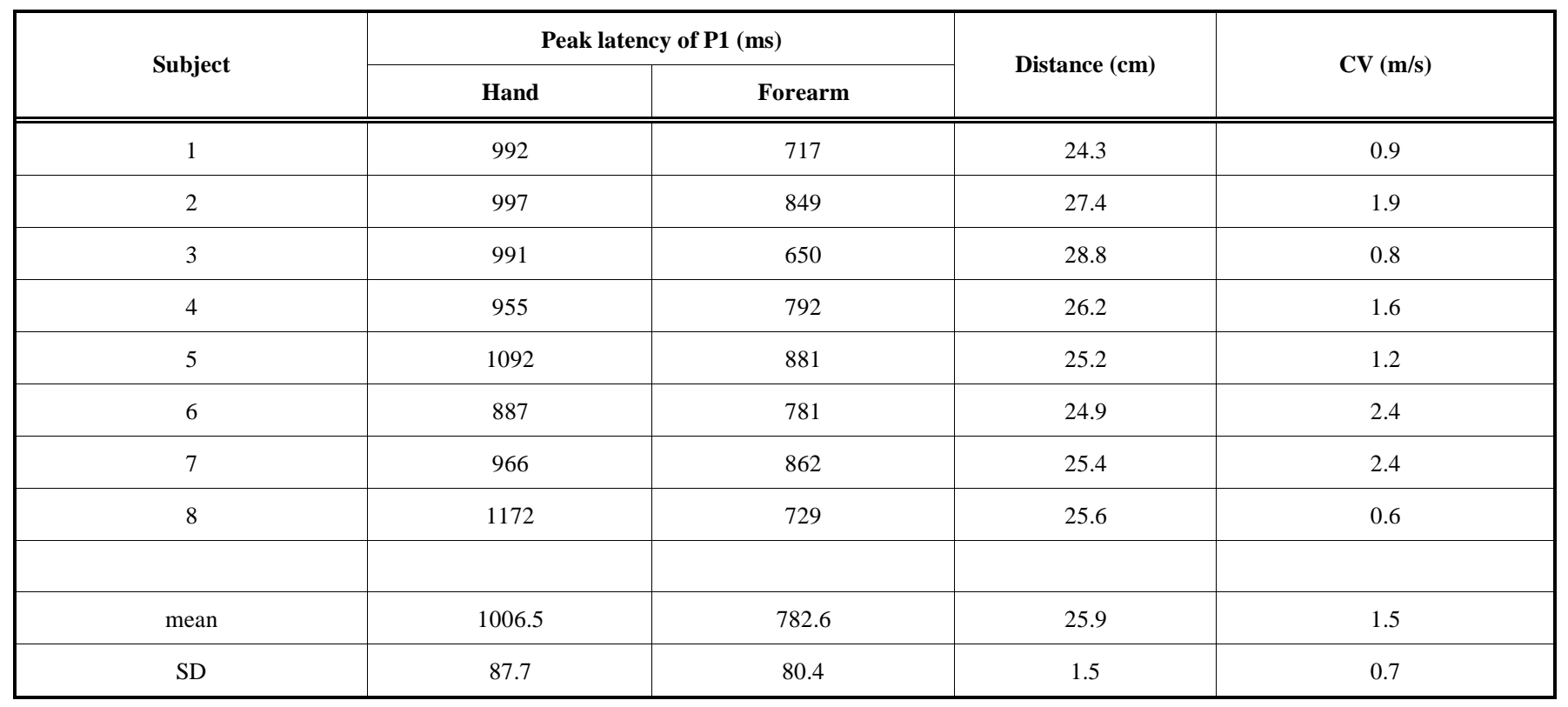

latency was difficult to identify. Thus, we used P1 for the analysis, which was large in amplitude and detected in all eight subjects. The mean P1 latency following hand and forearm stimulation was $1007 \mathrm{~ms}$ and $783 \mathrm{~ms}$, respectively (Table 1). The peripheral $\mathrm{CV}$ calculated from the latency difference of $\mathrm{P} 1$ was $1.5 \pm 0.7 \mathrm{~m} / \mathrm{s}$.

\section{DISCUSSION}

The stimulation did not elicit a $\mathrm{C}$ fiber-related sensation or EPs in two of ten subjects. This might be due to individual difference in thickness of the corneum. The electrode we used was consisted of an inner needle that protruded $0.1 \mathrm{~mm}$ from the outer ring and we used a very weak current for selective stimulation of $\mathrm{C}$-fibers. Therefore, in subjects with the thicker corneum, it is possible that the weak current could not reach to the epidermal area in which free nerve endings are located. Our previous study using a laser beam which is the most common way for activating $\mathrm{C}$ fibers also failed to elicit $\mathrm{C}$ fiber-related responses in four out of 17 subjects [26].

In the present study, $\mathrm{P} 1$ peaked at around $800 \mathrm{~ms}$ for the forearm and $1000 \mathrm{~ms}$ for the hand stimulation. In previous studies using a laser beam to a tiny area of skin [4, 9, 10, 27], which is known to selectively activate C fibers, the mean P1 latency for stimulation of the hand was 930-1144 ms, which is very similar to the present results. The estimated $\mathrm{CV}$ of $1.5 \mathrm{~m} / \mathrm{s}$ in this study was also consistent with previous studies showing a value of $0.8-2.8 \mathrm{~m} / \mathrm{s}$ by averaged EEG [4, 27, 28] and $0.4-1.8 \mathrm{~m} / \mathrm{s}$ [29] by microneurography. In terms of the precise measurement of $\mathrm{CV}$, microneurography is superior to EEG. However, since C-fibers have a very slow $\mathrm{CV}$, the latency difference between the two stimulation sites was enough long (224ms) to correctly detect by EEG. Another weakness of the present method is that we could not know receptive properties of $\mathrm{C}$ fibers unlike microneurography (for review, see [30]).
In addition, we also considered that our method mainly stimulated C fibers, since C fiber-related EPs do not appear on the concomitant activation of other fibers. For example, laser stimulation that activates both $\mathrm{A} \delta$ and $\mathrm{C}$ fibers elicits only the A $\mathrm{A}$ components without responses at latencies compatible with ultra-late components related to $\mathrm{C}$ fibers [31-33]. Likewise, C fiber-related cortical responses are only recorded when the concomitant activation of A fibers is suppressed, i.e. a pressure nerve block [34] or heating the skin below the A $\delta$ threshold [4]. In the present study, since there was no consistent response at a latency earlier than 400 $\mathrm{ms}$, the results suggested a selective activation of $\mathrm{C}$ fibers by our method.

Laser beams applied to a tiny area $[4,7,9,28,31,35]$ have been used to selectively activate $\mathrm{C}$ fibers, which is considered difficult to do with electrical stimulation, since $\mathrm{C}$ fibers generally have a high threshold to electrical stimulation. However, the present results indicate that this threshold is not so high when appropriate parameters are chosen. In support of this notion, unmyelinated afferents respond to skin deformation in mammals [36-38], and have a low mechanical threshold in human skin [39]. In addition, recent studies suggested that low-threshold $\mathrm{C}$ mechanoreceptive afferents provide information about pleasant touch [40-42], although their functional role remains unclear. In the present study, we used a very weak current (about 0.05 $\mathrm{mA}$ ) and half of the subjects felt the evoked sensation as a light touch. Therefore, it is possible that our method preferentially activates the low-threshold $\mathrm{C}$ fibers.

In conclusion, intra-epidermal electrical stimulation successfully activated cutaneous $\mathrm{C}$ fibers selectively. Because the method is easy to control and non-invasive, it should be useful for investigating the functions of small fibers both for basic research and for clinical examinations, although the parameters remain to be refined for a more consistent and stronger stimulation of $\mathrm{C}$ fibers, for example, by changing the waveform of the pulse or duration of the stimulus [43-45]. 


\section{REFERENCES}

[1] Plaghki L, Mouraux A. How do we selectively activate skin nociceptors with a high power infrared laser? Physiology and biophysics of laser stimulation. Neurophysiol Clin 2003; 33: 26977.

[2] Forss N, Raij TT, Seppa M, Hari R. Common cortical network for first and second pain. Neuroimage 2005; 24: 132-42.

[3] Kakigi R, Tran TD, Qiu Y, et al. Cerebral responses following stimulation of unmyelinated C-fibers in humans: electro- and magneto-encephalographic study. Neurosci Res 2003; 45: 255-75.

[4] Magerl W, Ali Z, Ellrich J, Meyer RA, Treede RD. C- and A deltafiber components of heat-evoked cerebral potentials in healthy human subjects. Pain 1999; 82: 127-37.

[5] Mouraux A, Guerit JM, Plaghki L. Refractoriness cannot explain why C-fiber laser-evoked brain potentials are recorded only if concomitant Adelta-fiber activation is avoided. Pain 2004; 112: 1626.

[6] Qiu Y, Inui K, Wang X, Nguyen BT, Tran TD, Kakigi R. Effects of distraction on magnetoencephalographic responses ascending through C-fibers in humans. Clin Neurophysiol 2004; 115: 636-46.

[7] Tran TD, Inui K, Hoshiyama M, Lam K, Qiu Y, Kakigi R. Cerebral activation by the signals ascending through unmyelinated $\mathrm{C}$-fibers in humans: a magnetoencephalographic study. Neuroscience 2002b; 113: 375-86

[8] Weiss T, Straube T, Boettcher J, Hecht H, Spohn D, Miltner WH. Brain activation upon selective stimulation of cutaneous $\mathrm{C}$ - and Adelta-fibers. Neuroimage 2008; 41: 1372-81.

[9] Qiu Y, Fu Q, Wang X, et al. Microneurographic study of C fiber discharges induced by $\mathrm{CO} 2$ laser stimulation in humans. Neurosci Lett 2003; 353: 25-8.

[10] Bragard D, Chen AC, Plaghki L. Direct isolation of ultra-late (Cfibre) evoked brain potentials by $\mathrm{CO} 2$ laser stimulation of tiny cutaneous surface areas in man. Neurosci Lett 1996; 209: 81-4.

[11] Inui K, Tsuji T, Kakigi R. Temporal analysis of cortical mechanisms for pain relief by tactile stimuli in humans. Cereb Cortex 2006; 16: 355-65.

[12] Inui K, Tran TD, Hoshiyama M, Kakigi R. Preferential stimulation of Adelta fibers by intra-epidermal needle electrode in humans. Pain 2002a; 96: 247-52.

[13] Inui K, Tran TD, Qiu Y, Wang X, Hoshiyama M, Kakigi R. Painrelated magnetic fields evoked by intra-epidermal electrical stimulation in humans. Clin Neurophysiol 2002b; 113: 298-304.

[14] Inui K, Tran TD, Qiu Y, Wang X, Hoshiyama M, Kakigi R. A comparative magnetoencephalographic study of cortical activations evoked by noxious and innocuous somatosensory stimulations. Neuroscience 2003; 120: 235-48.

[15] Wang X, Inui K, Qiu Y, Kakigi R. Cortical responses to noxious stimuli during sleep. Neuroscience 2004; 128: 177-86.

[16] Ogino $\mathrm{Y}$, Nemoto $\mathrm{H}$, Goto F. Somatotopy in human primary somatosensory cortex in pain system. Anesthesiology 2005; 103: 821-7.

[17] Nilsson HJ, Levinsson A, Schouenborg J. Cutaneous field stimulation (CFS): a new powerful method to combat itch. Pain 1997; 71: 49-55.

[18] Nilsson HJ, Schouenborg J. Differential inhibitory effect on human nociceptive skin senses induced by local stimulation of thin cutaneous fibers. Pain 1999; 80: 103-12.

[19] Rettay F. Electrical Nerve Stimmulation. Theory, Experiments and Applications. New York: Springer 1990.

[20] Kennedy WR, Wendelschafer-Crabb G. The innervation of human epidermis. J Neurol Sci 1993; 115: 184-90.

[21] Lauria G. Innervation of the human epidermis. A historical review. Ital J Neurol Sci 1999; 20: 63-70.

[22] Grill WM, Jr., Mortimer JT. The effect of stimulus pulse duration on selectivity of neural stimulation. IEEE Trans Biomed Eng 1996; 43: 161-6.

[23] Adriaensen H, Gybels J, Handwerker HO, Van Hees J. Suppression of $\mathrm{C}$-fibre discharges upon repeated heat stimulation may explain characteristics of concomitant pain sensations. Brain Res 1984; 302: 203-11.

[24] Torebjörk HE, Hallin RG. Responses in human A and C fibres to repeated electrical intradermal stimulation. J Neurol Neurosurg Psychiatry 1974; 37: 653-64.

[25] Opsommer E, Weiss T, Miltner WH, Plaghki L. Scalp topography of ultralate (C-fibres) evoked potentials following thulium YAG laser stimuli to tiny skin surface areas in humans. Clin Neurophysiol 2001; 112: 1868-74.

[26] Qui Y, Inui K, Wang X, Nguyen BT, Tran TD, Kakigi R. Effects of distraction on magnetoencephalographic responses ascending through C-fibers in humans. Clin Neurophysiol 2004; 115: 636-46.

[27] Tran TD, Lam K, Hoshiyama M, Kakigi R. A new method for measuring the conduction velocities of Abeta-, Adelta- and Cfibers following electric and $\mathrm{CO}(2)$ laser stimulation in humans. Neurosci Lett 2001; 301: 187-90.

[28] Tran TD, Inui K, Hoshiyama M, Lam K, Kakigi R. Conduction velocity of the spinothalamic tract following $\mathrm{CO} 2$ laser stimulation of C-fibers in humans. Pain 2002a; 95: 125-31.

[29] Vallbo AB, Hagbarth KE, Torebjörk HE, Wallin BG Somatosensory, proprioceptive, and sympathetic activity in human peripheral nerves. Physiol Rev 1979; 59: 919-75.

[30] Schmelz M, Schmidt R. Micoroneurographic single-unit recordings to assess receptive properties of afferent human $\mathrm{C}$ fibers. Neurosci Lett 2009; [Epub ahead of print].

[31] Cruccu G, Garcia-Larrea L. Clinical utility of pain--laser evoked potentials. Suppl Clin Neurophysiol 2004; 57: 101-10.

[32] Kakigi R, Inui K, Tamura Y. Electrophysiological studies on human pain perception. Clin Neurophysiol 2005; 116: 743-63.

[33] Treede RD, Lorenz J, Baumgartner U. Clinical usefulness of laserevoked potentials. Neurophysiol Clin 2003; 33: 303-14

[34] Bromm B, Neitzel H, Tecklenburg A, Treede RD. Evoked cerebral potential correlates of C-fibre activity in man. Neurosci Lett 1983 43: 109-14.

[35] Qiu Y, Inui K, Wang X, Tran TD, Kakigi R. Conduction velocity of the spinothalamic tract in humans as assessed by $\mathrm{CO}(2)$ laser stimulation of C-fibers. Neurosci Lett 2001; 311: 181-4.

[36] Kumazawa T, Perl ER. Primate cutaneous sensory units with unmyelinated (C) afferent fibers. J Neurophysiol 1977; 40: 132538

[37] Lynn B, Carpenter SE. Primary afferent units from the hairy skin of the rat hind limb. Brain Res 1982; 238: 29-43.

[38] Shea VK, Perl ER. Sensory receptors with unmyelinated (C) fibers innervating the skin of the rabbit's ear. J Neurophysiol 1985; 54: 491-501.

[39] Nordin M. Low-threshold mechanoreceptive and nociceptive units with unmyelinated (C) fibres in the human supraorbital nerve. J Physiol 1990; 426: 229-40.

[40] Olausson H, Wessberg J, Morrison I, McGlone F, Vallbo A. The neurophysiology of unmyelinated tactile afferents. Neurosci Biobehav Rev 2008; [Epub ahead of print].

[41] Olausson H, Lamarre Y, Backlund $\mathrm{H}$, et al. Unmyelinated tactile afferents signal touch and project to insular cortex. Nat Neurosci 2002; 5: 900-4

[42] Wessberg J, Olausson H, Fernstrom KW, Vallbo AB. Receptive field properties of unmyelinated tactile afferents in the human skin. J Neurophysiol 2003; 89: 1567-75.

[43] Fang ZP, Mortimer JT. Selective activation of small motor axons by quasi-trapezoidal current pulses. IEEE Trans Biomed Eng 2003; 38: 168-74.

[44] Vuckovic A, Rijkhoff NJ, Struijk JJ. Different pulse shapes to obtain small fiber selective activation by anodal blocking--a simulation study. IEEE Trans Biomed Eng 2004; 51: 698-706.

[45] Vuckovic A, Tosato M, Struijk JJ. A comparative study of three techniques for diameter selective fiber activation in the vagal nerve: anodal block, depolarizing prepulses and slowly rising pulses. J Neural Eng 2008; 5: 275-86. 